\title{
Um estudo sobre a relação do gênero versus temática abordada nos artigos publicados nas revistas científicas da área contábil no Brasil
}

\section{A study on the relationship of the gender versus thematic approach addressed in the articles published in the scientific journals of the accounting area in Brazil}

\author{
Jessica Cristhina Benedetti Batista ${ }^{1}$, Letícia Sanches Cristino ${ }^{2}$, Victor Biaggi \\ Evangelista $^{2}$, Angelo Antonio Davis de Oliveira Nunes e Rodrigues ${ }^{3}$
}

\begin{abstract}
Resumo
O presente estudo teve como objetivo apontar o perfil de produção científica em contabilidade por gênero no Brasil, mostrando qual a relação entre o gênero sexual e a temática abordada e publicada pelos pesquisadores(as) brasileiros(as). Assim, a estratégica metodológica caracterizou-se pela utilização de uma abordagem de pesquisa descritiva cujo problema de pesquisa é quantitativo. Na busca ao alcance do objetivo da pesquisa foi utilizada uma amostra intencional, que compreendeu sete revistas científicas, sendo que seis estão relacionadas a programas de pós-graduação em contabilidade e uma à entidade de classe ou de pesquisa. Os resultados apontam que a pesquisa científica em contabilidade está em crescente evolução, com predominância de autorias do gênero masculino, explorando temas principalmente relacionados às áreas de finanças e contabilidade gerencial, já as publicações de autoria feminina estão associadas aos temas de ensino, contabilidade financeira e contabilidade para instituições sem fins lucrativos/pública. Cabe ressaltar que as publicações, independente do gênero sexual, estão concentradas nas regiões Sul e Sudeste.
\end{abstract}

Palavras-chave: Gênero. Periódicos. Produção científica. Ciências Contábeis. Brasil.

\footnotetext{
${ }^{1}$ Especialização em Controladoria e Finanças pelo Centro Universitário da Fundação Educacional de Barretos (Unifeb), Barretos, São Paulo, Brasil.

${ }^{2}$ Especialização em Contabilidade e Tributos pelo Centro Universitário da Fundação Educacional de Barretos, Barretos, São Paulo, Brasil.

${ }^{3}$ Doutorado em Administração pela Universidade de São Paulo (USP), São Paulo, São Paulo, Brasil. Professor no Centro Universitário da Fundação Educacional de Barretos, Barretos, São Paulo, Brasil. E-mail: angelodavis@gmail.com
} 


\begin{abstract}
The present study aimed to show the profile of scientific production in accounting by gender in Brazil, showing the relationship between the sexual gender and the issue addressed and published by the Brazilian researchers. Thus the methodological strategy was characterized by the use of a descriptive research approach whose research problem is quantitative. In the search to reach the objective of the research was used an intentional sample, which comprised seven scientific journals, six of which are related to graduate programs in accounting and a class or research entities. The results point out that the scientific research in accounting is in increasing evolution, with predominance of authorship of the masculine gender, exploring subjects mainly related to the areas of finance and managerial accounting, already the publications of feminine authorship are associated to the subjects of education, financial accounting and accounting for non-profit/public institutions. It should be emphasized that publications, regardless of gender, are concentrated in the south and southeast regions.
\end{abstract}

Keywords: Gender. Journals. Scientific production. Accounting. Brazil.

\section{Introdução}

Nos últimos anos, tem-se observado um aumento no número de cursos de pós-graduação stricto sensu, no número de professores com dedicação exclusiva e na oferta de bolsas de pesquisa e iniciação científica na graduação e na pós-graduação, fatores esses que contribuem para um crescimento da produção científica contábil (DE LUCA et al., 2011; SOUZA et al., 2008).

Neste cenário de difusão acelerada do conhecimento contábil, percebe-se que discussões sobre produção científica na área de contabilidade é recente, tendo sido intensificada a partir dos anos 2000, com estudos que abordaram questões relacionadas ao tema das pesquisas, estratégias metodológicas, qualidade e rigor científico, o conteúdo e a forma, a autoria e as referências bibliográficas (SALM, 2016; SOUZA et al., 2008).

Sendo assim, as pesquisas da área contábil se deparam com algumas implicações sobre gênero, na qual se discute as diferenças entre homens e mulheres e o impacto provocado nos objetos de estudo. Sexo e gênero são duas formas de classificação da espécie humana que influenciam nas relações sociais. Enquanto sexo engloba questões biológicas, como cor da pele ou idade, o gênero engloba questões sociais e culturais. Gênero trata-se da construção social das diferenças do masculino e do feminino, que não possui relação com a sexualidade (LEMOS JUNIOR; SANTINI; SILVEIRA, 2015).

Especificamente no campo de produção científica há uma predominância do gênero masculino, embora as autorias femininas estejam aumentando ao longo dos anos, mas não ascendem com a mesma velocidade de seus colegas do gênero masculino (HAYASHI et al., 2007; LETA, 2003).

Em observância ao fato dos homens dominarem a produção científica da área contábil é possível notar que as pesquisadoras femininas encontram alguns obstáculos para se sobressaírem aos homens, tais como o escasso reconhecimento dentro da própria comunidade científica, a sobrecarga devido ao acúmulo das tradicionais funções do lar e a dificuldade de conciliar as demandas da própria profissão (BRUSCHINI; PUPPIN, 2004; DE LUCA et al., 2011; SOARES, 2001).

Diante da disparidade de gênero existente na produção científica em contabilidade, o presente estudo busca responder a seguinte problemática: "qual a relação entre o gênero sexual e a temática abordada pelos pesquisadores brasileiros?".

Assim, a presente pesquisa tem como principal objetivo apontar o perfil da produção científica em contabilidade por gênero no Brasil.

Para o alcance do objetivo em questão, elaborou-se um instrumento de pesquisa contendo algumas variáveis que permitem identificar 
características das publicações em contabilidade de autorias masculinas e femininas, e assim, por meio do teste não paramétrico do qui-quadrado verificar-se-á se os temas abordados pelos autores diferem de seu gênero sexual.

O desenvolvimento deste estudo se mostra relevante pelo fato de analisar o comportamento da produção científica da contabilidade, mais precisamente sobre a relação entre os temas explorados e o gênero sexual dos autores, de forma que possa contribuir para que um perfil da produção dessa área do conhecimento seja estabelecido.

Considerando-se o exposto, a presente pesquisa está dividida em cinco seções, sendo a primeira a iniciar por esta introdução. A segunda é composta por um referencial teórico que contextualiza a produção científica na área contábil, enquanto a terceira seção aborda os aspectos metodológicos. Na quarta seção é evidenciada a análise dos resultados e na quinta e última seção serão apresentadas as considerações finais.

\section{A Pesquisa Científica em Contabilidade e o Gênero Sexual}

A pesquisa científica é um processo de investigação que consiste em identificar o conhecimento científico que se deseja buscar e sua inferência em termos absolutos, mas para alcançar os resultados esperados o pesquisador necessita adquirir uma postura investigativa e estar devidamente preparado em base teórica sobre o assunto (SALM, 2016).

Nesse contexto, a publicação científica assume o papel fundamental na produção do conhecimento, disseminando os resultados de pesquisas em periódicos estabelecidos na comunidade científica, servindo como referência para praticantes e pesquisadores (AMARAL et al., 2014; LEITE FILHO, 2008; VOLPATO, 2008).

Assim, inserem-se os programas de pósgraduação, cuja finalidade é a formação de pesquisadores, professores, mestres e doutores que contribuem para produção e propagação do conhecimento (SOUZA et al., 2008).
Nos últimos anos a área do saber foi fortemente influenciada pelas transformações tecnológicas que modificaram o processo produtivo do conhecimento, facilitando os meios para divulgação e publicação, proporcionando um aumento no número de trabalhos publicados por pesquisadores e cientistas (LIMA; DINIZ; SILVA, 2013).

Esses avanços também proporcionaram a criação de um conjunto de procedimentos que visam avaliar e classificar os periódicos científicos, bem como seus veículos de divulgação, servindo como um fator motivador para a melhoria e aprimoramento da qualidade dos periódicos e consequentemente das pesquisas (BAUMGARTEN, 2010; CORDEIRO et al., 2014).

Cabe ressaltar que, no cenário científico o princípio geral é "publicar ou perecer", pois as pesquisas publicadas são utilizadas como principal indicador da qualidade do pesquisador, influenciando até mesmo nos sistemas de prestígios e recompensas, inclusive financeiras (MIRANDA et al., 2013; NJOKU; VAN DER HEIJDEN; INANGA, 2010).

A pesquisa científica em contabilidade no Brasil vem apresentando crescimento ao longo dos anos, entretanto há um consenso de que o desenvolvimento da pesquisa contábil no País possui certa defasagem qualitativa e temporal em relação aos mercados mais desenvolvidos, ou seja, o conhecimento científico da contabilidade, no âmbito nacional, tem se disseminado de maneira lenta (DANTAS et al., 2011; RIBEIRO, 2013).

Mendonça Neto et al. (2004) asseveram que um dos fatores que contribuem para a tardia difusão da pesquisa contábil é a baixa produtividade dos autores nacionais da área contábil em relação aos internacionais e até mesmo aos colegas de áreas correlatas como administração.

Nesse contexto, Oler, Oler e Skousen (2010) evidenciaram que além da baixa produtividade, os autores da área contábil visam com certa predominância realizar pesquisas acerca de temas relacionados aos temas de finanças e economia. 
Ademais, há indícios que os pesquisadores da contabilidade tendem a publicar de forma isolada, indicando um quadro com falta de grupos com publicações periódicas e ainda o fato das publicações denotarem autorias com predominância do gênero masculino (LEITE FILHO, 2008).

Em relação à pesquisa científica sob o ponto de vista da equidade de proporções entre gêneros é notória a disparidade existente, uma vez que os cursos de pós-graduação que são o ponto de partida do processo de formação de pesquisadores apresentam diferenças significativas entre os alunos matriculados do sexo masculino e feminino (VELHO; LEON, 1998).

De acordo com Soares (2001), a baixa participação feminina na área científica se deve ao fato das mulheres não conseguirem conciliar a sobrecarga resultante do acúmulo das funções do lar e da profissão acadêmica, fato que gera o escasso reconhecimento dentro da própria comunidade acadêmica e a dificuldade em ajustar as demandas da própria profissão e aquelas da profissão do parceiro.

No entanto, considerando os obstáculos citados acima, nas últimas décadas, tem-se notado um aumento significativo do avanço da atuação feminina no campo da ciência contábil, mas ainda em níveis inferiores quando se comparado ao gênero masculino (DE LUCA et al., 2011).

O resultado da baixa participação do gênero feminino na produção científica, seja em qualquer área do conhecimento, é denominado no cenário acadêmico como gender tracking ou a concentração de gênero em um determinado tema, como a predominância feminina em temas relacionados à educação contábil, física e engenharia (MIRANDA et al., 2013; VELHO; LEON, 1998).

De modo conclusivo, dada à evolução da produção científica em contabilidade, surge a necessidade de que novos estudos sejam realizados com o intuito de investigar e consequentemente facilitar a compreensão de tal fenômeno, sendo assim a análise da influência do gênero sexual no desenvolvimento das pesquisas também se mostra relevante (DE LUCA et al., 2011).

\section{Estudos anteriores}

Ao buscar estudos anteriores sobre o tema, identificaram-se pesquisas que abordaram questões relacionadas ao gênero sexual e as linhas de pesquisa na produção científica em contabilidade. Algumas dessas pesquisas, mais estreitamente ligadas ao tema do presente estudo são apresentadas na sequência.

O estudo realizado por Leite Filho (2008) explorou a produtividade científica dos autores em anais de congressos e periódicos na área de contabilidade e os resultados apontaram que há uma padronização de publicação na área, predominância de autores do sexo masculino, indícios de forte endogenia de instituições nacionais e existência de concentração de autoria vinculada.

Já a pesquisa realizada por Souza et al. (2008) teve como objetivo analisar as instituições de ensino superior da área de ciências contábeis e seus pesquisadores, por meio de sua produção científica. Os resultados apontaram que as temáticas controladoria e contabilidade gerencial e contabilidade para usuários externos são predominantes, enquanto que a área de ensino é a menos explorada.

De Luca et al. (2011) objetivaram analisar a participação feminina na produção científica em contabilidade publicada nos anais dos Encontros da Associação Nacional de Pós-Graduação e Pesquisa em Administração (EnANPAD), dos Congressos USP de Controladoria e Contabilidade e da Associação Nacional dos Programas de PósGraduação em Ciências Contábeis. (ANPCONT). Foram analisados 1.294 artigos, utilizando-se pesquisa documental, com enfoque bibliométrico na Lei de Lotka. Os autores constataram que a participação feminina na produção científica contábil é significativamente pequena em relação à do gênero masculino e que sua evolução acompanha a quantidade total de autores.

A pesquisa desenvolvida por Miranda et al. (2013) mostrou-se relevante por citar tema ensino como a linha de pesquisa em contabilidade com o menor percentual de trabalhos defendidos no 
programa de doutorado da Universidade de São Paulo. No entanto, o estudo revelou que essa linha de pesquisa é a que possui a maior presença de autoras do sexo feminino.

Salm (2016) constatou que no período de 2012 a 2014, as teses defendidas nos programas de pós-graduação em contabilidade no Brasil abordaram principalmente temas relacionados à contabilidade financeira e contabilidade gerencial. Já com relação ao gênero sexual, houve uma predominância de autores do sexo masculino no período analisado.

\section{Metodologia}

O presente estudo está estruturado metodologicamente a partir de um objetivo descritivo, com problema quantitativo. De acordo com Beuren (2014) e Martins (2011), uma pesquisa descritiva tem como objetivo expor os aspectos e características de determinada população ou fenômeno. Portanto, esta pesquisa se caracteriza como descritiva, pois busca identificar e comparar o perfil de produção científica em contabilidade por gênero sexual no País.

Para Richardson (2014), um estudo quantitativo possui a intenção de garantir a precisão dos resultados, evitando distorções de análise e interpretação a partir da escolha de técnicas estatísticas para descrição e explicação dos fenômenos. Nesse estudo, será utilizado o teste não paramétrico do qui-quadrado para testar a relação entre o gênero sexual e a temática abordada pelos pesquisadores brasileiros.

A amostra intencional e não probabilística compreendeu 1056 artigos das áreas de finanças, ensino da contabilidade, contabilidade financeira, contabilidade gerencial, contabilidade para instituições sem fins lucrativos (ISFL) e contabilidade pública, publicados em periódicos de programas de mestrado e doutorado em contabilidade no período de 2010 a 2015, enquadrados nos estratos A2, B1, B3 e B4 da classificação Qualis. Após a coleta dos artigos, foi possível elencar sete periódicos nacionais, conforme evidenciados no Quadro 1.

Quadro 1 - Revistas científicas brasileiras.

\begin{tabular}{|l|c|c|}
\hline \multicolumn{1}{|c|}{ Revistas } & Siglas & IES \\
\hline Contabilidade Vista \& Revista & CVR & UFMG \\
\hline Revista Custos e @gronegócio On line & RCA & UFRPE \\
\hline Revista de Contabilidade e Finanças & RCF & USP \\
\hline Revista de Educação e Pesquisa em Contabilidade & REPEC & FBC \\
\hline Revista de Finanças Aplicadas & RFA & USP \\
\hline Revista de Gestão, Finanças e Contabilidade & RGFC & UNEB \\
\hline Revista Universo Contábil & RUC & FURB \\
\hline
\end{tabular}

Fonte: Autores

Considerando o total de 1056 artigos selecionados para compor a amostra, 161 trabalhos foram retirados por serem internacionais e apresentarem autores com nomes estrangeiros, dificultando assim a identificação do gênero sexual. A quantidade final de artigos foi de 895 trabalhos.
Para coleta dos dados, foi desenvolvido um instrumento de pesquisa composto por oito variáveis, envolvendo informações gerais sobre os artigos. O Quadro 2 apresenta as variáveis, bem como um breve relato sobre as informações compreendidas por cada variável. 
Quadro 2 - Variáveis da pesquisa.

\begin{tabular}{|l|l|}
\hline Variáveis & \multicolumn{1}{|c|}{ Conteúdo } \\
\hline Temática & $\begin{array}{l}\text { Esta variável evidencia em qual linha de pesquisa o tema abordado está inserido (ensino } \\
\text { da contabilidade, finanças, contabilidade financeira, contabilidade gerencial, terceiro setor). }\end{array}$ \\
\hline Revista & Compreende o nome do periódico onde o artigo foi publicado. \\
\hline Volume & $\begin{array}{l}\text { O volume de cada edição corresponde ao número sequencial do ano calendário, contado a } \\
\text { partir do ano de fundação da revista. }\end{array}$ \\
\hline Número & O número da edição corresponde ao número sequencial da edição em cada volume. \\
\hline $\begin{array}{l}\text { Ano de } \\
\text { publicação }\end{array}$ & O ano em que o artigo tornou-se público. \\
\hline Autor & Esta variável apresenta o nome de cada autor que publicou o artigo. \\
\hline Gênero & $\begin{array}{l}\text { Esta variável classifica os autores de acordo com o gênero sexual, ou seja, em masculino ou } \\
\text { feminino. }\end{array}$ \\
\hline Região & $\begin{array}{l}\text { Compreende a região geográfica que pertence à instituição na qual está vinculado primeiro } \\
\text { autor do artigo. }\end{array}$ \\
\hline
\end{tabular}

Fonte: Autores

A análise dos dados foi realizada por meio de técnicas estatísticas descritivas e pelo teste não paramétrico qui-quadrado que busca verificar a existência de diferença significativa entre grupos independentes e uma determinada característica, ou se essas diferenças são devidas ao acaso (DOWNING; CLARK, 2011).

A utilização do teste qui-quadrado teve como finalidade verificar se as temáticas abordadas pelos pesquisadores brasileiros diferem do gênero sexual dos mesmos. Dessa forma, a hipótese nula $\left(H_{0}\right)$ a ser testada afirma que não há diferença entre a temática em contabilidade selecionada e o sexo do pesquisador, consequentemente a hipótese alternativa $\left(H_{1}\right)$ afirma que existe relação de dependência entre a temática e o sexo do pesquisador.

Os dados foram tabulados e analisados por meio do software estatístico Statiscal Package for the Social Sciences ${ }^{\circledR}\left(\right.$ SPSS $\left.^{\circledR}\right)$, adotando-se o nível de significância 0,05 .

\section{Análise dos Resultados}

Esta seção contém a descrição e análise dos dados coletados. Inicialmente é apresentada uma análise exploratória e em seguida os resultados do teste não paramétrico qui-quadrado que possibilitou alcançar o objetivo da pesquisa.

Tabela 1 - Ano de publicação.

\begin{tabular}{|c|c|c|c|c|c|}
\hline \multirow{2}{*}{ Ano de publicação } & \multicolumn{4}{|c|}{ Autorias } & \multirow{2}{*}{ Total } \\
\hline & Femininas & $\%$ & Masculinas & $\%$ & \\
\hline 2010 & 104 & 34,4 & 198 & 65,6 & 302 \\
\hline 2011 & 111 & 33,7 & 218 & 66,3 & 329 \\
\hline 2012 & 171 & 33,9 & 334 & 66,1 & 505 \\
\hline 2013 & 184 & 36,1 & 326 & 63,9 & 510 \\
\hline 2014 & 171 & 32,6 & 353 & 67,4 & 524 \\
\hline 2015 & 190 & 34,3 & 364 & 65,7 & 554 \\
\hline
\end{tabular}

Fonte: Autores 
Analisando os dados da Tabela 1, verificase que durante o período estudado o nível de publicações acadêmicas na área contábil aumentou gradativamente com predominância de autoria masculina. No entanto, é possível notar que as autorias do gênero feminino também aumentaram ao longo dos anos, com exceção de 2014 que apresentou uma redução significativa em relação ao ano de 2013.

$\mathrm{O}$ aumento da quantidade nominal de mulheres nas publicações científicas em contabilidade no período pode ser reflexo do crescente interesse das mulheres pela área contábil. Segundo Sillas (2011), em 1990 as mulheres representavam $41,92 \%$ do total de entrantes dos cursos de contabilidade, mas 10 anos depois, em 2000, a participação feminina aumentou para $45,39 \%$. Já a pesquisa realizada por Lemos Junior, Santini e Silveira (2015) constatou uma evolução constante no número de mulheres exercendo a profissão de contadora no período de 2004 a 2011.

Tabela 2 - Publicações científicas em contabilidade por regiões brasileiras.

\begin{tabular}{lcccccc}
\hline \multirow{2}{*}{ Regiões } & Artigos & $\mathbf{\%}$ & \multicolumn{4}{c}{ Autorias } \\
\cline { 5 - 7 } & & & Femininas & \% & Masculinas & $\%$ \\
\hline Centro-Oeste & 77 & 8,6 & 61 & 6,5 & 169 & 9,4 \\
Nordeste & 145 & 16,2 & 190 & 20,4 & 276 & 15,4 \\
Norte & 19 & 2,1 & 21 & 2,3 & 46 & 2,6 \\
Sudeste & 415 & 46,4 & 350 & 37,5 & 830 & 46,3 \\
Sul & 239 & 26,7 & 311 & 33,3 & 470 & 26,3 \\
\hline Total & 895 & 100 & 933 & 100 & 1791 & 100 \\
\hline
\end{tabular}

Fonte: Autores

Na Tabela 2 pode-se verificar a distribuição das publicações científicas em contabilidade por regiões brasileiras, considerando o gênero das autorias.

No tocante às publicações por regiões brasileiras, a Região com o maior número de publicações é a Sudeste, com um total de 415 artigos e a menor é a Região Norte com apenas 19 trabalhos. Com relação às autorias do sexo masculino a maior participação pertence ao Sudeste com $46,3 \%$ e a menor é Norte com 2,6\%. Analisando as publicações femininas a Região Norte apresenta a menor participação $(2,3 \%)$ e a Região Sudeste a maior $(37,5)$.
De modo geral, é possível constatar uma hegemonia da Região Sudeste na quantidade de trabalhos publicados e nas autorias, sejam masculinas ou femininas. No entanto, as autorias masculinas são predominantes em todas as regiões, resultado esse que vai ao encontro do que foi notado por De Luca et al. (2011) que verificaram uma supremacia da Região Sudeste e de autorias masculinas nas publicações em anais de três eventos nacionais no período de 2004 a 2009.

A Tabela 3 apresenta a quantidade de artigos publicados no período classificados de acordo com o gênero sexual e a temática abordada. 
Tabela 3 - Publicações científicas por área da contabilidade.

\begin{tabular}{|c|c|c|c|c|c|c|}
\hline \multirow{2}{*}{ Área } & \multirow{2}{*}{ Artigos } & \multirow{2}{*}{$\%$} & \multicolumn{4}{|c|}{ Autorias } \\
\hline & & & Femininas & $\%$ & Masculinas & $\%$ \\
\hline Ensino & 104 & 11,6 & 144 & 15,5 & 187 & 10,4 \\
\hline Finanças & 223 & 24,9 & 165 & 17,7 & 459 & 25,6 \\
\hline Contabilidade financeira & 212 & 23,7 & 237 & 25,5 & 400 & 22,3 \\
\hline Contabilidade gerencial & 300 & 33,5 & 326 & 35,0 & 642 & 35,8 \\
\hline Contabilidade ISFL/pública & 56 & 6,3 & 59 & 6,3 & 105 & 5,9 \\
\hline Total & 895 & 100 & 933 & 100 & 1791 & 100 \\
\hline
\end{tabular}

Fonte: Autores

Analisando-se a Tabela 3, é possível verificar que a área da contabilidade com o maior número de artigos científicos publicados é a contabilidade gerencial, apresentando um total de 300 trabalhos; em contrapartida, a área com o menor número de publicações é a ISFL/pública com apenas 56 pesquisas.

De modo análogo, sob a ótica das autorias, a contabilidade gerencial possui a maior participação de autores masculinos (35,8\%) e femininos $(35,0 \%)$ e a área de ISFL/pública a menor participação de autoras $(6,3 \%)$ e autores
$(5,9 \%)$. Tais resultados podem estar relacionados à tendência de os alunos na graduação darem maior importância às disciplinas ligadas à profissão contábil, como constatado por Corrêa, Antonovz e Espejo (2009), que identificaram a contabilidade gerencial como uma das disciplinas mais importantes segundo a percepção dos alunos e a contabilidade pública como uma das menos importantes.

Na Tabela 4 evidencia-se a quantidade de artigos publicados durante o período analisado, considerando a temática abordada e o periódico.

Tabela 4 - Autorias por periódico e temática.

\begin{tabular}{|c|c|c|c|c|c|c|c|c|c|c|c|c|}
\hline \multirow{3}{*}{ Revistas } & \multicolumn{10}{|c|}{ Área } & \multirow{2}{*}{\multicolumn{2}{|c|}{ Total }} \\
\hline & \multicolumn{2}{|c|}{ Ensino } & \multicolumn{2}{|c|}{ Finanças } & \multicolumn{2}{|c|}{$\begin{array}{c}\text { Contabilidade } \\
\text { financeira }\end{array}$} & \multicolumn{2}{|c|}{$\begin{array}{c}\text { Contabilidade } \\
\text { gerencial }\end{array}$} & \multicolumn{2}{|c|}{$\begin{array}{l}\text { Contabilidade } \\
\text { ISFL/pública }\end{array}$} & & \\
\hline & $\mathbf{N}$ & $\%$ & $\mathbf{N}$ & $\%$ & $\mathbf{N}$ & $\%$ & $\mathbf{N}$ & $\%$ & $\mathbf{N}$ & $\%$ & $\mathbf{N}$ & $\%$ \\
\hline REPEC & 108 & 32,6 & 48 & 7,7 & 96 & 15,1 & 91 & 9,4 & 44 & 26,8 & 387 & 14,2 \\
\hline RFA & 0 & 0,0 & 139 & 22,3 & 37 & 5,8 & 26 & 2,7 & 0 & 0,0 & 202 & 7,4 \\
\hline RCA & 24 & 7,3 & 96 & 15,4 & 108 & 17,0 & 483 & 49,9 & 0 & 0,0 & 711 & 26,1 \\
\hline RGFC & 41 & 12,4 & 65 & 10,4 & 86 & 13,5 & 61 & 6,3 & 31 & 18,9 & 284 & 10,4 \\
\hline CVR & 52 & 15,7 & 99 & 15,9 & 73 & 11,5 & 105 & 10,8 & 38 & 23,2 & 367 & 13,5 \\
\hline RUC & 76 & 23,0 & 80 & 12,8 & 132 & 20,7 & 153 & 15,8 & 30 & 18,3 & 471 & 17,3 \\
\hline RCF & 30 & 9,1 & 97 & 15,5 & 105 & 16,5 & 49 & 5,1 & 21 & 12,8 & 302 & 11,1 \\
\hline Total & 331 & 100 & 624 & 100 & 637 & 100 & 968 & 100 & 164 & 100 & 2724 & 100 \\
\hline
\end{tabular}

Fonte: Autores

$\mathrm{N}=$ quantidade de autorias.

De acordo com a Tabela 4 é possível notar que a revista REPEC apresentou o maior número de autorias sobre o tema ensino, representando $32,6 \%$ de todas as autorias, no entanto o periódico
RFA não publicou nenhuma pesquisa sobre o referido tema. Analisando o tema finanças pode-se verificar que de um total de 624 autorias em todos os periódicos explorados, a revista RFA possui a 
maior participação, com 22,3\%; em contrapartida, a menor foi verificada na revista REPEC.

Com relação à temática contabilidade financeira, o periódico com a menor participação evidenciada foi a RFA $(5,8 \%)$ e com a maior a RUC (20,7\%). Já as revistas RCA e REPEC se destacaram respectivamente nos temas contabilidade gerencial e contabilidade para ISFL/ pública, com 49,9\% e $26,8 \%$ de participação. Ainda, sobre a temática contabilidade para ISFL/ pública é possível observar que os periódicos RFA e RCA não apresentaram publicações.

$\mathrm{Na}$ Tabela 5 evidencia-se o resultado do teste qui-quadrado e os resíduos ajustados, cujo intuito é analisar o grau de associação entre o gênero sexual e os temas abordados pelos pesquisadores brasileiros.

Tabela 5 - Teste qui-quadrado das variáveis temática e gênero.

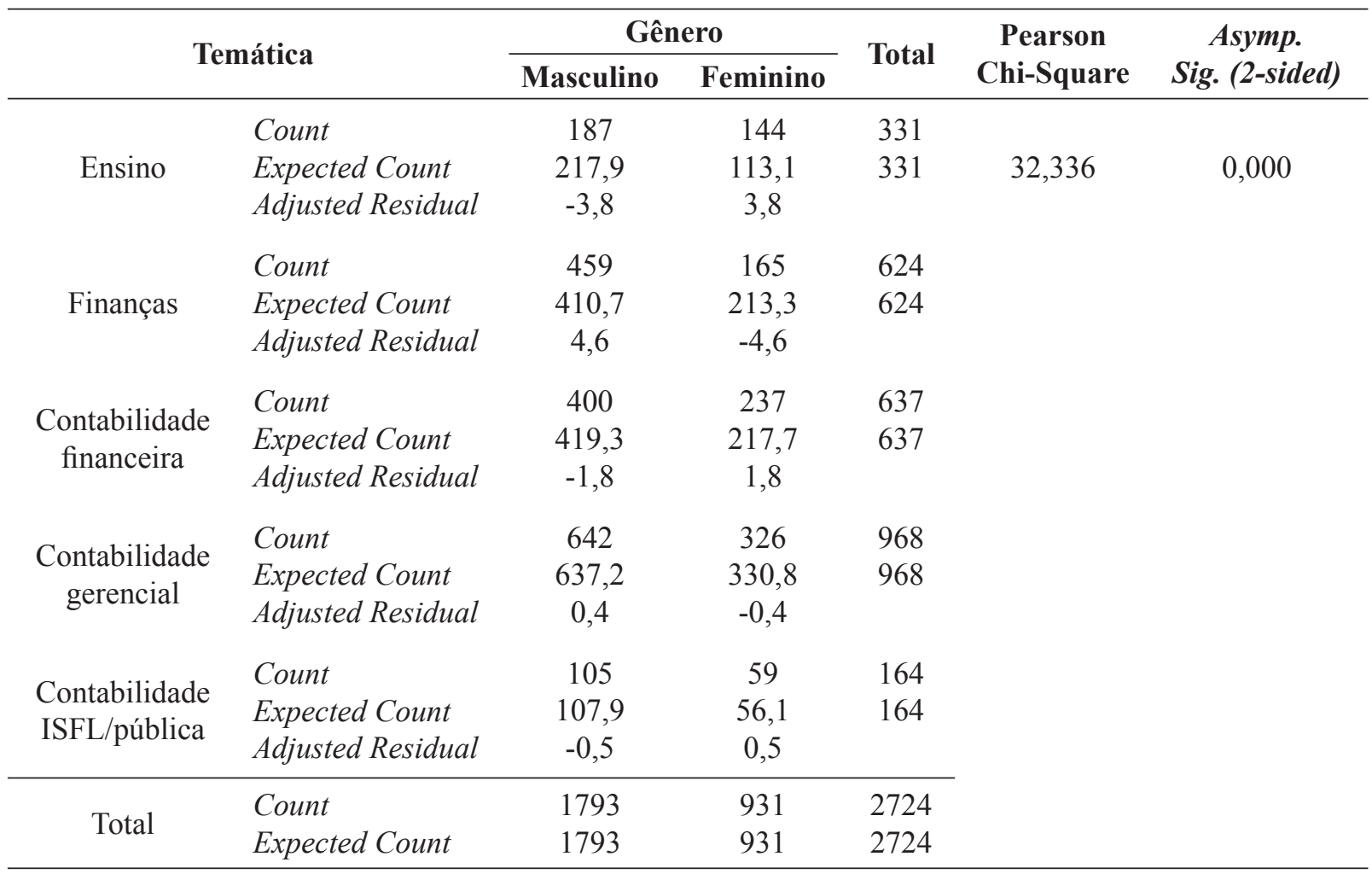

Fonte: Autores (elaborada por meio do software SPSS $^{\circledR}$ )

0 células $(0 \%)$ têm frequência esperada menor que 5 . A frequência mínima esperada é 56,05 .

Count $=$ frequência observada.

Expected Count $=$ frequência esperada.

Adjusted Residual $=$ resíduos ajustados.

A frequência observada de autorias masculinas que abordaram os temas de finanças e contabilidade gerencial foi maior que a frequência esperada. Em contrapartida, a frequência observada das autorias desse gênero, cujo tema dos artigos foi ensino, contabilidade financeira e contabilidade ISFL/pública foram menores que o esperado. Com relação às autorias do gênero feminino, os temas sobre finanças e contabilidade gerencial apresentaram frequências observadas inferiores às esperadas, já os temas de ensino, contabilidade financeira e contabilidade ISFL/ pública, as frequências observadas foram maiores que as esperadas.

O resultado do teste qui-quadrado (Pearson Chi-Square) para as variáveis temática e gênero foi de 32,336 com um nível de significância igual 0,000. Assim, rejeita-se a hipótese nula $\left(\mathrm{H}_{0}\right)$ e 
aceita-se a hipótese que indica associação entre as variáveis.

Nesse contexto, a Tabela 6 apresenta o grau de associação entre as variáveis analisadas pelo teste qui-quadrado, representado pelo coeficiente de contingência.

Tabela 6 - Coeficiente de contingência das variáveis temática e gênero.

\begin{tabular}{llcc}
\hline & & Value & Approx. Sig. \\
\hline Nominal by Nominal & Contingency Coefficient & 0,108 & 0,00 \\
$\mathbf{N}$ of Valid Cases & & 2724 & \\
\hline
\end{tabular}

Fonte: Autores (elaborada por meio do software SPSS $^{\circledR}$ )

Segundo Bruni (2009), o coeficiente de contingência pode variar entre 0 e 1 , e quanto mais próximo a 1 maior será o grau de associação entre as variáveis. Sendo assim, é possível estabelecer que há um nível de associação fraca $(0,108)$ entre as variáveis temática e gênero, mas estatisticamente significativa a um nível de confiança de $5 \%$.

Diante do exposto, os trabalhos publicados cujas autorias pertencem ao gênero feminino estão associados aos temas de ensino, contabilidade financeira e contabilidade para ISFL/pública. Em contrapartida, as publicações de autorias masculinas estão associadas aos temas de finanças e contabilidade gerencial.

Com o intuito de ratificar os resultados citados, a Tabela 7 evidencia o resultado do teste qui-quadrado para as variáveis revista e gênero, que posteriormente será confrontado com o resultado do teste para as variáveis temática e gênero (Tabela 5) e com as informações sobre os temas publicados pelas revistas (Tabela 4).

Tabela 7 - Teste qui-quadrado das variáveis revista e gênero.

\begin{tabular}{|c|c|c|c|c|c|c|}
\hline & \multirow{2}{*}{ Temática } & \multicolumn{2}{|c|}{ Gênero } & \multirow{2}{*}{ Total } & \multirow{2}{*}{$\begin{array}{c}\text { Pearson } \\
\text { Chi-Square }\end{array}$} & \multirow{2}{*}{$\begin{array}{c}\text { Asymp. } \\
\text { Sig. (2-sided) }\end{array}$} \\
\hline & & Masculino & Feminino & & & \\
\hline \multirow{3}{*}{ REPEC } & Count & 238 & 149 & 387 & \multirow{3}{*}{14,648} & \multirow{3}{*}{0,023} \\
\hline & Expected Count & 254,7 & 132,3 & 387 & & \\
\hline & Adjusted Residual & $-1,9$ & 1,9 & & & \\
\hline \multirow{3}{*}{ RFA } & Count & 144 & 58 & 202 & & \\
\hline & Expected Count & 133,0 & 69,0 & 202 & & \\
\hline & Adjusted Residual & 1,7 & $-1,7$ & & & \\
\hline \multirow{3}{*}{$\mathrm{RCA}$} & Count & 463 & 248 & 711 & & \\
\hline & Expected Count & 468,0 & 243,0 & 711 & & \\
\hline & Adjusted Residual & $-0,5$ & 0,5 & & & \\
\hline \multirow{3}{*}{ RGFC } & Count & 178 & 106 & 284 & & \\
\hline & Expected Count & 186,9 & 97,1 & 284 & & \\
\hline & Adjusted Residual & $-1,2$ & 1,2 & & & \\
\hline \multirow{3}{*}{ CVR } & Count & 239 & 128 & 367 & & \\
\hline & Expected Count & 241,6 & 125,4 & 367 & & \\
\hline & Adjusted Residual & $-0,3$ & 0,3 & & & \\
\hline
\end{tabular}


Continuação

\begin{tabular}{llccc} 
& Count & 310 & 161 & 471 \\
\multirow{2}{*}{ RUC } & Expected Count & 310 & 161 & 471 \\
& Adjusted Residual & 0,0 & 0,0 & \\
& Count & 221 & 81 & 302 \\
\multirow{2}{*}{ RCF } & Expected Count & 198,8 & 103,2 & 302 \\
& Adjusted Residual & 2,9 & $-2,9$ & \\
\hline \multirow{2}{*}{ Total } & Count & 1793 & 931 & 2724 \\
& Expected Count & 1793 & 931 & 2724
\end{tabular}

Fonte: Autores (elaborada por meio do software SPSS ${ }^{\circledR}$ )

0 células $(0 \%)$ têm frequência esperada menor que 5 . A frequência mínima esperada é 69,04 .

Count $=$ frequência observada.

Expected Count $=$ frequência esperada.

Adjusted Residual = resíduos ajustados.

Analisando a Tabela 7, nota-se que as revistas RFA e RCF apresentaram frequências observadas de autorias masculinas superiores às esperadas. Com relação às autorias femininas, os periódicos REPEC, RCA, RGFC e CVR revelam frequências observadas superiores às esperadas. Cabe ressaltar que a revista RUC evidenciou uma igualdade entre os valores observados e esperados para ambos os gêneros.

Logo, esses resultados denotam indícios de que os periódicos RFA e RCF estão associados às autorias do gênero masculino e as revistas REPEC, RCA, RGFC e CVR com as autorias do gênero feminino, pois o resultado do teste qui-quadrado (Pearson Chi-Square) para as variáveis revista e gênero foi de 14,648 com um nível de significância igual 0,023 . Assim, rejeita-se a hipótese nula $\left(\mathrm{H}_{0}\right)$ e aceita-se a hipótese da dependência das variáveis com presença de associação.

No tocante, a solidificar a referida análise, a Tabela 8 evidencia o coeficiente de contingência para as variáveis revista e gênero.

Tabela 8 - Coeficiente de contingência das variáveis revista e gênero.

\begin{tabular}{lccc}
\hline & & Value & Approx. Sig. \\
\hline Nominal by Nominal & Contingency Coefficient & 0,073 & 0,023 \\
$\mathbf{N}$ of Valid Cases & & 2724 & \\
\hline
\end{tabular}

Fonte: Autores (elaborada por meio do software SPSS $^{\circledR}$ )

Não assumindo a hipótese nula.

Utilizando o erro padrão assintótico assumindo a hipótese nula.

$\mathrm{O}$ resultado do coeficiente de contingência revela um nível de associação entre as variáveis revista e gênero de 0,073 . No entanto, esse nível de combinação entre essas variáveis é um pouco inferior em relação ao nível apresentado pelas variáveis temática e gênero (Tabela 6).

Sendo assim, considerando os resultados é possível estabelecer que os pesquisadores do gênero masculino tendem a abordar em suas pesquisas o tema de finanças, uma vez que o teste qui-quadrado indicou associação entre essas variáveis. Cabe ressaltar que o mesmo teste revelou certo nível de associação entre as autorias do gênero masculino e as revistas RFA e RCF, cujo tema finanças é respectivamente abordado em $22,3 \%$ e $15,5 \%$ (Tabela 4) dos trabalhos publicados. 
Vale salientar que o periódico RUC registrou a frequência esperada para autorias masculinas e esta revista publicou 15,8\% (Tabela 4) das pesquisas que abordaram o tema contabilidade gerencial, resultados esses que ratificam o fato do tema contabilidade gerencial estar associado ao gênero masculino (Tabela 5).

Com relação às autorias do gênero feminino é possível verificar associação com os temas ensino, contabilidade financeira e contabilidade para ISFL/pública. $O$ presente gênero ainda apresentou associação com os periódicos REPEC, RCA, RGFC e CVR, revistas essas que cujos temas mais abordados em suas publicações foram ensino, contabilidade financeira e contabilidade para ISFL/pública.

Cabe ressaltar, que como no gênero masculino a revista RUC registrou a frequência esperada paras as autorias femininas e a maior parte das pesquisas publicadas em seus volumes abordaram os temas ensino e contabilidade financeira.

Assim, é possível concluir que a participação feminina na publicação científica contábil ainda é pequena, mas está em crescente evolução ao longo dos anos, fato esse também constatado por De Luca et al. (2011), Leite Filho (2008) e Santos e Carlin (2012). No tocante às temáticas abordadas pelos gêneros, destaca-se a tendência dos autores masculinos selecionarem os temas sobre finanças e contabilidade gerencial e o gênero feminino optar pelos temas ensino, contabilidade financeira e contabilidade para ISFL/pública, resultado esse que corrobora com a pesquisa realizada por Miranda et al. (2013) que observaram predominância feminina em publicações sobre o tema ensino.

\section{Considerações Finais}

O propósito da presente pesquisa foi apontar o perfil de produção científica em contabilidade por gênero no Brasil, mostrando a relação entre o gênero e a temática abordada pelos pesquisadores brasileiros.
De modo geral, por meio da análise foi possível observar que durante o período analisado a pesquisa científica em contabilidade está em crescente evolução, com predominância de autorias do gênero masculino, explorando temas principalmente voltados às áreas de finanças e contabilidade gerencial, concentrando as publicações nas regiões Sul e Sudeste.

No tocante, a verificar se havia diferença significativa entre o gênero sexual e as temáticas abordadas nas pesquisas, o teste qui-quadrado evidenciou que há um certo nível de dependência com associação entre o gênero masculino e os temas de finanças e contabilidade gerencial. Já o gênero feminino apresentou um nível de associação com as temáticas ensino, contabilidade financeira e contabilidade para ISLF/pública.

Adicionalmente, com a aplicação do mesmo teste considerando o gênero sexual e os periódicos analisados, constata-se que as revistas RFA e RCF possuem associação com o gênero masculino e as revistas REPEC, RCA, RGFC e CVR apresentaram associação com o gênero feminino. Consequentemente, os periódicos associados ao gênero masculino publicaram um maior número de pesquisas que abordaram os temas associados ao respectivo gênero, ocorrendo o mesmo com o feminino.

Assim, esse estudo contribuiu na identificação das áreas de finanças e contabilidade gerencial como temas relacionados às pesquisas de autoria masculina e as áreas de ensino, contabilidade financeira e contabilidade para ISFL/pública referentes às publicações de autorias femininas como características do perfil da produção científica em contabilidade no Brasil.

Com o intuito de contribuir para que novas pesquisas possam surgir sobre o tema, sugerese que seja realizada uma análise epistemológica das técnicas estatísticas e metodologias utilizadas nos artigos, considerando o gênero sexual, com a finalidade de verificar possíveis diferenças na qualidade entre as publicações masculinas e femininas. 


\section{Referências}

AMARAL, M. R.; SANTANA, C. M.; SALES, I. C. H.; ARAUJO NETO, L. M. Perfil dos autores na produção científica em mercado financeiro de crédito e de capitais nos congressos USP de controladoria e contabilidade e congresso ANPCONT. Revista Evidenciação Contábil \& Finanças, João Pessoa, v. 2, n. 2, p. 55-68, 2014. Disponível em: https://bit.ly/2ZVyPLA. Acesso em: 15 nov. 2017.

BAUMGARTEN, M. Avaliação de periódicos científicos e a base Qualis: um debate sobre produtividade. In: FÓRUM DE EDITORES DE PERIÓDICOS CIENTÍFICOS DA UFRGS, 5., 2010, Porto Alegre, RS. Anais. [...]. Porto Alegre, RS: UFRGS, 2010. Disponível em: https://bit. ly/3eetWmj. Acesso em: 3 abr. 2017.

BEUREN, I. M. Como elaborar trabalhos monográficos em contabilidade: teoria e pratica. 3. ed. São Paulo: Atlas, 2014.

BRUNI, A. L. SPSS aplicado à pesquisa acadêmica. São Paulo: Atlas, 2009.

BRUSCHINI, C.; PUPPIN, A. B. Trabalho de mulheres executivas no Brasil no final do século XX. Cadernos de Pesquisa, São Paulo, v. 34, n. 121, p. 105-138, 2004. Disponível em: https://bit. ly/2O8L1DB. Acesso em: 29 nov. 2017.

CORDEIRO, R. A.; SANCHES, P. L. B.; CAVAlCANTE, K. de O.; LEITE, J. C. de L. Pesquisa quantitativa em finanças: uma análise das técnicas estatísticas utilizadas por artigos científicos publicados em periódicos qualificados no triênio 2007 a 2009. Revista de Administração da UFSM, Santa Maria, v. 7, n. 1, p. 117-134, 2014. Disponível em: https://bit.ly/3fdN3OH. Acesso em: 10 set. 2017.

CORRÊA, M. D.; ANTONOVZ, T.; ESPEJO, M. M. S. B. A percepção dos alunos sobre a importância das disciplinas do currículo do curso de ciências contábeis: reflexões diante do contexto contemporâneo. In: ENCONTRO DE ENSINO E PESQUISA EM ADMINISTRAÇÃO E CONTABILIDADE, 2., 2009, Curitiba, PR. Anais [...]. Curitiba: ANPAD, 2009. p. 1-15. Disponível em: https://bit.ly/3f9mcDf. Acesso em: 3 abr. 2017.
DANTAS, J. A.; SILVA, C. T.; SANTANA, C. M.; VIEIRA, E. T. Padrões de comunicação cientifica em contabilidade: um comparativo entre a revista contabilidade e finanças e a the accounting review. Revista Contemporânea de Contabilidade, Florianópolis, v. 8, n. 16, p. 11-36, 2011. Disponível em: https://bit.ly/3iKMtKj. Acesso em: 15 nov. 2017.

DE LUCA, M. M. M.; GOMES, C. A. S.; CORRÊA, D. M. M. C.; DOMINGOS, S. R. M. Participação feminina na produção cientifica em contabilidade publicada nos anais dos eventos ENANPAD, congresso USP de controladoria e contabilidade congresso ANPCONT. Revista de Contabilidade e Organizações, São Paulo, SP, v. 5, n. 1, p. 145-164, 2011. Disponível em: https://bit. ly/3iJeKkp. Acesso em: 7 dez. 2017.

DOWNING, D.; CLARK, J. Estatística aplicada. Tradução de Alfredo Alves de Farias, 3. ed. São Paulo: Saraiva, 2011.

HAYASHI, M. C. P. I.; CASTRO, R. C.; COSTA, M. D. P. R. da; HAYASHI, C. R. M. Indicadores da participação feminina em ciência e tecnologia. Revista Transformação, Campinas, SP, v. 19, n. 2, p. 169-187, 2007. Disponível em: https://bit. ly/3iNEMTN. Acesso em: 3 mar. 2017.

LEITE FILHO, G. A. Padrões da produtividade de autores em periódicos e congressos na área de contabilidade no Brasil: um estudo bibliométrico. Revista de Administração Contemporânea, Curitiba, PR, v. 12, n. 2, p. 533-554, 2008. Disponível em: https://bit.ly/3iLGaGw. Acesso em: 3 mar. 2017.

LEMOS JUNIOR, L. C.; SANTINI, R. B.; SILVEIRA, N. S. P. A feminização da área contábil: um estudo qualitativo básico. Revista de Educação e Pesquisa em Contabilidade, Brasília, DF, v. 9, n. 1, p. 64-83, 2015. Disponível em: https://bit. ly/2O5YfRk. Acesso em: 14 abr. 2017.

LETA, J. As mulheres na ciência brasileira: crescimento, contrastes e um perfil de sucesso. Estudos Avançados, São Paulo, SP, v. 17, n. 49, p. 271-184, 2003. Disponível em: https://bit. 1y/2Cn2THT. Acesso em: 2 abr. 2017. 
LIMA, F. D. C.; DINIZ, J. R.; SILVA, D. M. Perfil de produção cientifica em contabilidade: um comparativo entre os periódicos contabilidade vista \& revista e universo contábil, no período de 2006 a 2010. Revista de Administração, Contabilidade e Economia, Joaçaba, v. 12, n. 2, p. 607-640, 2013. Disponível em: https://bit.ly/3eah5Bz. Acesso em: 2 abr. 2017.

MARTINS, G. A. Manual para elaboração de monografias e dissertações. 3. ed. São Paulo: Atlas, 2011.

MENDONÇA NETO, O. R.; CARDOSO, R. L.; RICCIO, E. L.; SAKATA, M. C. G. Estudo sobre as publicações científicas em contabilidade: uma análise de 1990 até 2003. In: ENCONTRO DA ASSOCIAÇÃO NACIONAL DOS PROGRAMAS DE PÓS-GRADUAÇÃO EM ADMINISTRAÇÃO, 28., 2004, Curitiba, PR. Anais [...]. Curitiba: ANPAD, 2004. Disponível em: https://bit.ly/2O8DnsJ. Acesso em: 3 abr. 2017.

MIRANDA, G. J.; SANTOS, L. D. A. A.; NOVA, S. P. D. C. C.; CORNACCHIONE JÚNIOR, E. B. (2013). A pesquisa em educação contábil: produção científica e preferências de doutores no período de 2005 a 2009. Revista de Contabilidade \& Finanças, São Paulo, SP, v. 24, n. 61, p. 7588, 2013. Disponível em: https://bit.ly/3ebt7dF. Acesso em: 2 abr. 2017.

NJOKU, J. C.; VAN DER HEIJDEN, B. I. J. M.; INANGA, E. L. Fusion of expertise among accounting faculty: towards an expertise model for academia in accounting. Critical Perspectives on Accounting, Amsterdan, v. 21, n. 1, p. 51-52, 2010. Disponível em: https://bit.ly/2Cf0GOR. Acesso em: 17 nov. 2017.

OLER, D. K.; OLER, M. J.; SKOUSEN, C. Characterizing accounting research. Accounting Horizons, Lakewood Ranch, v. 24, n. 4, p. 635679, 2010. Disponível em: https://bit.ly/2W1RRie. Acesso em: 17 nov. 2017.

RIBEIRO, H. C. M. Revista contemporânea de contabilidade: uma análise do perfil da produção acadêmica durante o período de 2004 a 2012. Revista Contemporânea de Contabilidade, Florianópolis, SC, v. 10, n. 20, p. 3-28, 2013. Disponível em: https://bit.ly/2ZfIGx0. Acesso em: 3 mar. 2017.
RICHARDSON, R. J. Pesquisa social: métodos e técnicas. 3. ed. São Paulo: Atlas, 2014.

SALM, D. C. Produção cientifica em contabilidade no Brasil: um perfil das teses de doutoradono período de 2012-2014. 2016. Monografia (Bacharelado em Ciências Contábeis) - Universidade Federal de Santa Catarina, SC, Florianópolis, 2016.

SANTOS, P. R. P.; CARLIN, D. O. Análise da produção cientifica do congresso ANPCONT: um estudo bibliométrico sobre o processo de convergência aos padrões internacionais de contabilidade. Revista ConTexto, Porto Alegre, RS, v. 12, n. 22, p. 131-144, 2012. Disponível em: https://bit.ly/2Cf0Sxz. Acesso em: 3 mar. 2017.

SILLAS, E. P. Mulheres contabilistas: um estudo do nível de estresse das profissionais atuantes no Estado do Paraná. 2011. Dissertação (Mestrado em Contabilidade) - Universidade Federal do Paraná, PR, Curitiba, 2011.

SOARES, T. A. Mulheres em ciência e tecnologia: ascensão limitada. Química Nova, Recife, PE, v. 24, n. 2, p. 281-285, 2001. Disponível em: https:// bit.ly/2AOfLXq. Acesso em: 3 mar. 2017.

SOUZA, F. C. de; ROVER, S.; GALLON, A. V.; ENSSLIN, S. R. Análise das IES da área de ciências contábeis e de seus pesquisadores por meio de sua produção cientifica. Contabilidade Vista \& Revista, Belo Horizonte, MG, v. 19, n. 3, p. 1538, 2008. Disponível em: https://bit.ly/2ObJqwM. Acesso em: 3 mar. 2017.

VELHO, L.; LEON, E. A construção social da produção cientifica por mulheres. Cadernos Pagu, Campinas, SP, v. 5, n. 10, p. 309-344, 1998. Disponível em: https://bit.ly/38IiQ80. Acesso em: 3 mar. 2017.

VOLPATO, G. L. Publicação cientifica. 3. ed. Botucatu: Cultura Acadêmica, 2008.

Recebido em: 14 fev. 2020

Aceito em: 15 maio 2020 